\title{
Nuevo dispositivo para el aislamiento de la fracción estromal vascular a partir de lipoaspirados humanos: método de obtención y análisis de calidad celular

\author{
New device for stromal vascular fraction isolation from \\ human lipoaspirates: method and cell quality analysis
}

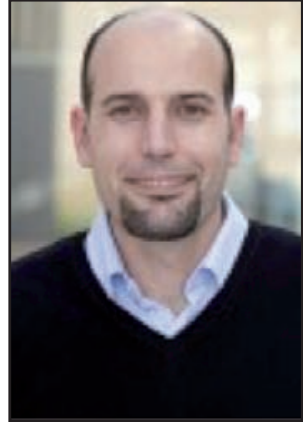

Dos-Anjos, S.

Dos-Anjos, S. *, Mercader, J.**, Katz., AJ ${ }^{\star * *}$., Llull, R. ****

Resumen

El tejido adiposo obtenido mediante liposucción es una fuente idónea para aislar células con potencial terapéutico, las denominadas células de la fracción estromal vascular (FEV), que incluyen células madre mesenquimales. Estas células se han convertido en una de las principales herramientas de terapia celular autóloga para diversas aplicaciones médicas, y en los últimos años se han ido desarrollando diversas tecnologías para su aislamiento y uso clínico.

En este trabajo presentamos un nuevo método rápido, sencillo y eficiente para el aislamiento de células de la FEV mediante un dispositivo médico cerrado que permite recoger y procesar lipoaspirados humanos en el mismo procedimiento quirúrgico de manera coste-efectiva. Además describimos los métodos llevados a cabo para cuantificar la calidad, seguridad y eficacia del inóculo celular obtenido.

\author{
Palabras clave Tejido adiposo, Lipoaspirado, \\ Lipoinfiltración, \\ Fracción estromal vascular.
}

Código numérico 19-104-15841
The adipose tissue obtained by liposuction is an abundant source to isolate regenerative cells, the stromal vascular fractions cells (SVF), including adipose mesenchymal stem cells. These cells have became an excellent tool for autologous cell therapy in different clinical applications, and several platforms for adipose tissue processing have been developed for SVF isolation.

In this study we describe a new medical device for SVF isolation from human lipoaspirates, using a fast, efficient and user-friendly procedure in the same surgical act in a cost-effective way. Additionally, we present different methods to guarantee the quality, safety and potency of the cell inoculum obtained.

$\begin{array}{ll}\text { Key words } & \text { Adipose tissue, Lipoaspirate, } \\ & \text { Lipofilling, } \\ & \text { Stromal vascular fraction. }\end{array}$

Numeral Code $\quad$ 19-104-15841

\footnotetext{
* Biólogo, Stem-Center, Clínica Palmaplanas, Palma de Mallorca, España.

** Bioquímico, Stem-Center, Clínica Palmaplanas, Palma de Mallorca, España.

*** Especialista en Cirugía Plástica y Reconstructiva. Division of Plastic and Reconstructive Surgery, University of Florida, USA.

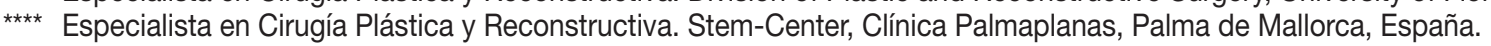




\section{Introducción}

A lo largo de la última década, estudios de diferentes grupos de investigación han demostrado que la gran mayoría de tejidos del cuerpo humano poseen células progenitoras que presentan cierta capacidad de proliferación y diferenciación hacia distintos linajes celulares. Estas células cumplen funciones de reparación de pequeñas lesiones y también sirven de recambio para sustituir otras células que mueren o desaparecen como consecuencia del proceso de envejecimiento (1).

De entre todos los tejidos, el adiposo se ha convertido en uno de los más estudiados en los últimos años dado que suele ser abundante en el cuerpo humano, es un tejido accesorio y de fácil obtención y además es una fuente muy rica de células con propiedades regenerativas $(2,3)$.

El tejido adiposo se ha considerado tradicionalmente como un tejido inerte. Sin embargo desde el descubrimiento de células madre mesenquimales pluripotenciales en los lipoaspirados (4) y la descripción del método, relativamente sencillo para su obtención (18), hemos asistido a un interés creciente por su uso en medicina regenerativa. Este descubrimiento realizado por los Drs. Llull y Katz, así como el aislamiento y posibles usos de las células madre mesenquimales, se plasmaron en la patente "231" (US 6,777,231 Patent).

La liposucción o aspiración del tejido adiposo es en la actualidad uno de los procedimientos estéticos más realizados en el mundo. Aunque habitualmente se realiza con el objetivo de eliminar la grasa corporal sobrante y modelar la figura, cada vez se utilizan más los lipoaspirados como fuente para aislar células con potencial terapéutico, las denominadas células de la fracción estromal vascular (FEV).

La FEV comprende una población heterogénea de células con distintas funciones que se obtienen tras lavado, digestión y centrifugación de una muestra de lipoaspirado. El procedimiento detallado para su aislamiento se explicará a lo largo de este trabajo. Entre los tipos celulares que forman parte de la FEV destacan entre otros (5-7):

- Preadipocitos: células que darán lugar a adipocitos maduros.

- Fibroblastos: células encargadas de sintetizar y organizar la matriz extracelular del tejido adiposo.

- Células madre mesenquimales adultas: con capacidad de diferenciación hacia distintos linajes celulares y de control celular.

- Células con capacidad inmunomoduladora: monocitos, macrófagos, linfocitos, etc.

- Progenitores hematopoyéticos, pericitos: cuya función es estabilizar la formación de nuevos vasos sanguíneos.

Las células madre derivadas del tejido adiposo (CM) presentes en la fracción estromal vascular, son capaces de diferenciarse en diversas líneas celulares tales como: adipogénica, condrogénica, osteogénica y otras, ofre- ciendo un apoyo adicional para su uso terapéutico (8). Esta capacidad morfogénica o transdiferenciativa de las CM (en particular de aquellas derivadas del tejido adiposo) es la que ha hecho que se consideren una de las grandes expectativas en medicina regenerativa. Estas células son capaces de liberar multitud de factores con capacidad angiogénica (9), inmunomoduladora $(10,11)$, mitogénica, sintética o antiapoptótica (12).

En la actualidad, muchos grupos y centros de investigación han centrado su actividad en la expansión en cultivo celular y posterior utilización de las células madre mesenquimales a partir de la FEV procedente de lipoaspirados humanos. Sin embargo, las células que comprenden la FEV, por sí mismas, son suficientes y capaces en muchos casos de desempeñar funciones reparativas y regenerativas. Se han desarrollado diversos ensayos clínicos en este sentido $(13,17)$. Además, la utilización de células en fresco, sin manipulaciones sustanciales, y de forma autóloga, no plantea problemas éticos ni regulatorios, lo cual es muy propicio para su utilización clínica siempre y cuando el procesamiento e implantación se realicen en el mismo acto quirúrgico y sin alterar la función esencial de las células aisladas.

El uso de las células terminalmente diferenciadas obtenidas del estroma del tejido adiposo junto con $\mathrm{CM}$ capacita una estrategia terapéutica amplia en patologías asociadas a cicatrización, revascularización y modulación de la respuesta inmune innata y adquirida (14).

Existen actualmente en el mercado distintas plataformas semiautomatizadas que permiten el aislamiento de células de la FEV a partir de tejido adiposo humano (Celution $^{\circledR}$, Tissue-Genesis ${ }^{\circledR}$, Sepax $^{\circledR}$, etc); sin embargo, su elevado coste impide en términos generales su utilización clínica.

En este trabajo describimos los pasos necesarios para aislar de forma rápida y eficiente una gran cantidad de células de la FEV mediante la utilización de un nuevo dispositivo cerrado que permite el procesamiento de grandes cantidades de lipoaspirado humano. Analizamos también distintos parámetros relacionados con la calidad, seguridad y eficacia de las células obtenidas, con el objetivo de que puedan ser utilizadas de forma clínica con la mayor garantía de éxito.

\section{Material y Método}

Para este trabajo utilizamos un total de 24 muestras de tejido adiposo humano procedentes de liposucciones. Las zonas donantes fueron: abdomen, flancos y cara interna de los muslos, principalmente. Todas las pacientes fueron mujeres que mediante consentimiento informado permitieron la utilización de estas muestras con propósito de investigación. La gran mayoría de estas pacientes fueron sometidas a aumento mamario con tejido adiposo autólogo enriquecido con células de la FVE. La edad media (media +/- desviación estándar (DP)) fue de 37,56 


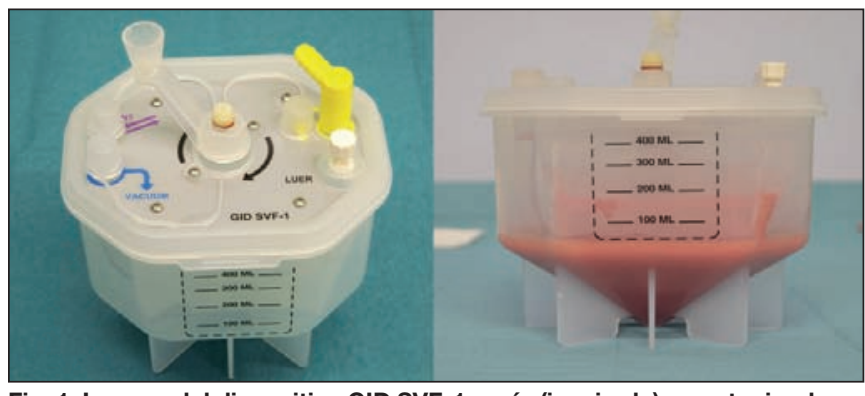

Fig. 1. Imagen del dispositivo GID SVF-1 vacío (izquierda) y conteniendo un lipoaspirado crudo, sin procesar (derecha).

+/- 11,94 años, con un rango de 21 a 56 años. El índice de masa corporal (IMC) medio fue de $20+/-2$. Ninguna paciente presentaba infección, enfermedad o alteración endocrina concomitante. La recogida del tejido adiposo se realizó mediante aspiración utilizando el dispositivo Microaire ${ }^{\circledR}$ y cánulas de punta roma tipo mercedes de $4 \mathrm{~mm}$ de diámetro, previa infiltración de la zona donante mediante solución salina fisiológica y adrenalina.

Para el aislamiento de la FEV utilizamos un dispositivo médico cerrado (GID SVF-1) (Fig. 1) que permite la recogida directa del lipoaspirado desde la cánula de liposucción, así como el procesamiento del mismo de forma rápida y sencilla (The GID Group Inc, Colorado, EE.UU.).

El procedimiento empleado, de forma resumida, fue el siguiente:

- Tres lavados consecutivos del tejido adiposo utilizando solución Ringer Lactado suplementada con antibióticos y heparina.

- Digestión enzimática durante 40 minutos a $37^{\circ} \mathrm{C}$ en agitación utilizando el reactivo GIDzyme-2 (The GID Group Inc, Colorado, EE.UU.).

- Inactivación del enzima mediante albúmina humana al 2,5\% y centrifugación a $800 \mathrm{~g}$ durante 10 minutos para obtener el pellet celular (tejido comprimido) que contiene la FVE (Fig. 2).

- Este pellet se resuspendió en $20 \mathrm{ml}$ de Ringer Lactato mediante una aguja espinal de 14 G (Abbocath) y la suspensión celular obtenida se analizó mediante distintos métodos que se describen a continuación.

La determinación del número de células nucleadas obtenido, viabilidad celular, índices de proliferación y apoptosis se realizó utilizando el dispositivo Nucleocounter NC-3000 (Chemometec, Dinamarca) y los kits suministrados por el fabricante. Asimismo, se realizó la confirmación manual mediante una cámara de contaje Neubauer en el microscopio de contraste de fases (Nikon Eclipse Ti).

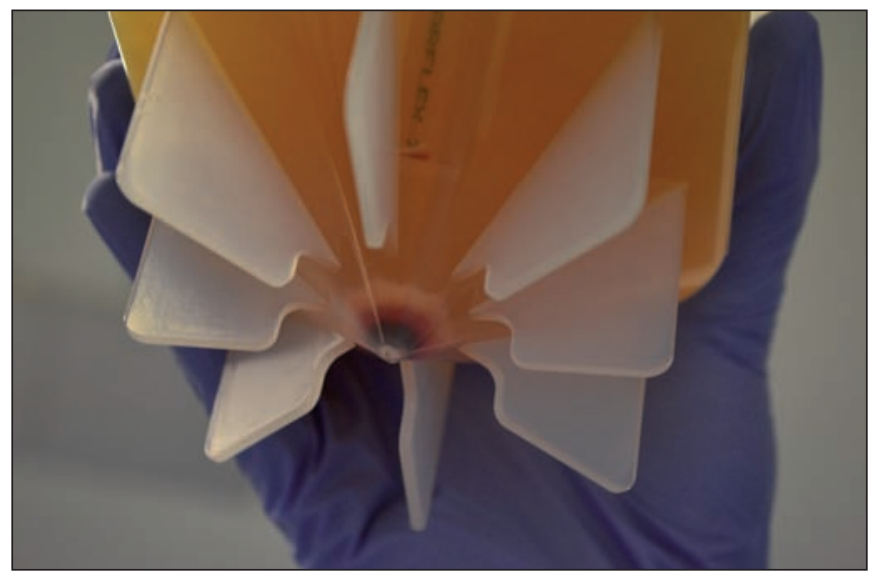

Fig. 2. Imagen que muestra el pellet celular que contiene la FVE, tras disociación y centrifugación del lipoaspirado utilizando el dispositivo GID SVF-1.

La determinación de los niveles de endotoxinas en la suspensión celular se efectuó utilizando el dispositivo Endosafe-PTS siguiendo las recomendaciones específicas del fabricante (Charles River).

Los ensayos de potencia (eficacia) se realizaron mediante el cultivo celular de células de la FVE en matrigel para determinar capacidad angiogénica, y co-incubación de las mismas en presencia de PBMCs (células mononucleares de sangre periférica) para determinar la capacidad inmunomoduladora a través de la inhibición de la proliferación.

\section{RESULTADOS \\ Análisis de calidad \\ 1. Rendimiento y viabilidad celular}

Las células de la FVE fueron analizadas para determinar el número obtenido y su viabilidad. Los resultados se expresan como número de células nucleadas totales y viables por cada centímetro cúbico de lipoaspirado seco procesado (media \pm SEM). También se muestra el porcentaje de viabilidad celular. Los datos específicos obtenidos se presentan en la Tabla I. Los valores de rendimiento celular obtenido de la FVE fueron de unas 600.000 células nucleadas por cada mililitro de tejido adiposo seco procesado -ausencia de fluidos- (Tabla I). Los datos de viabilidad media obtenidos estuvieron en torno al $80 \%$.

\section{2. Índice apoptótico}

La mayor parte de células viables (no apoptóticas) se acumulan en el cuadrante superior derecho (aproximadamente el 80\%) (Fig. 3); cuando un porcentaje importante de células están dañadas o en proceso apoptótico, se produce un desplazamiento hacia el cuadrante inferior.

Tabla I. Contaje y viabilidad celular

\begin{tabular}{|c|c|c|}
\hline $\begin{array}{c}\text { Células nucleadas totales /cc } \\
\text { tejido adiposo seco }\end{array}$ & $\begin{array}{c}\text { Células nucleadas viables /cc } \\
\text { tejido adiposo seco }\end{array}$ & \% Viabilidad Celular \\
\hline $\begin{array}{c}656.413 \pm 107964 \\
(\text { Mean } \pm \text { SEM })(n=14)\end{array}$ & $\begin{array}{c}548.275 \pm 97543 \\
(\text { Mean } \pm \text { SEM })(n=14)\end{array}$ & $82.73 \pm 2.49$ \\
$($ Mean \pm SEM $)(n=14)$
\end{tabular}




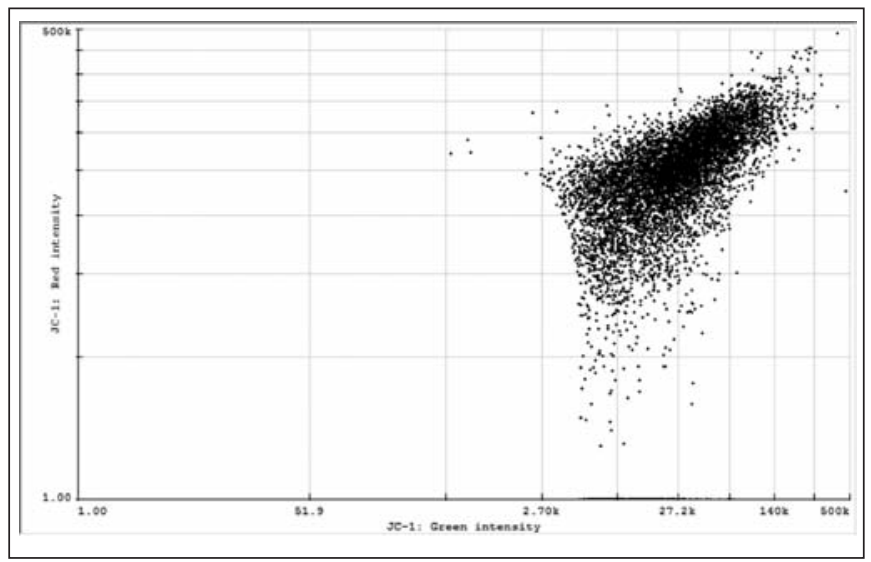

Fig. 3. Imagen representativa (scatter plot) obtenida por citometría de la muestra de células de la FEV marcadas con el colorante JC-1. Permite medir procesos apoptóticos mediante variaciones del potencial de membrana mitocondrial a través de fluorescencia.

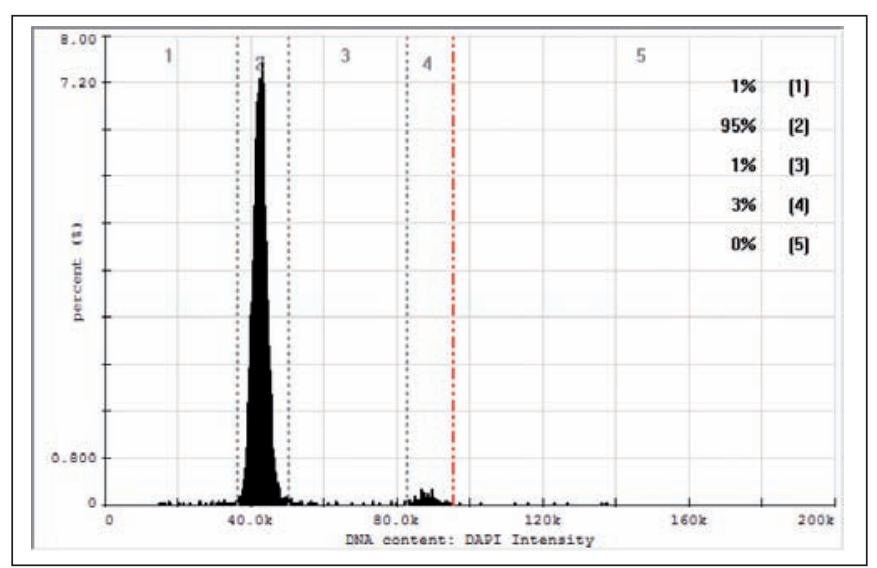

Fig. 4. Imagen representativa de histogramas de ADN obtenidos utilizando el kit 2-step cell cycle assay (Chemometec ${ }^{\circledR}$, Dinamarca) en células FVE frescas.

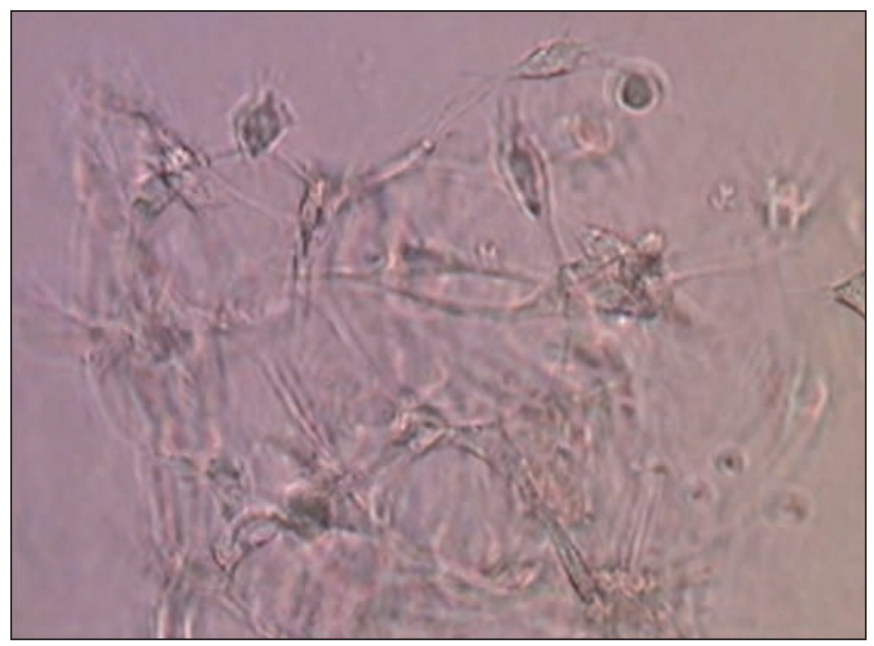

Fig. 5. Células FVE tras 15 días de cultivo in vitro en matrigel. Se observa cómo las células se organizan en redes complejas. Imagen obtenida mediante microscopio de contraste de fases Nikon Eclipse Ti-S (100 X).

\section{Ciclo celular (índice de proliferación)}

El contenido de ADN celular se analizó mediante citometría de imagen. La gran mayoría de células (en torno al $95 \%$ ) están en fase G0/G1 (estado de reposo, sin proliferar, pico 2), mientras que solamente un 2-4 \% de las células están en proliferación (poblaciones 3-4 en fases $\mathrm{S}$ y G2/M) (Fig. 4).
Tabla II. Valores de endotoxina obtenidos en la suspensión celular (EU/ml).

\begin{tabular}{|c|}
\hline Niveles de endotoxina $\mathbf{E U} / \mathrm{ml}$ \\
\hline $1,9 \mathrm{EU} / \mathrm{ml}$ \\
\hline
\end{tabular}

Análisis de seguridad de la suspensión celular obtenida 1. Nivel de endotoxinas

Los valores encontrados en todas las muestras analizadas fueron siempre muy inferiores al límite permitido por la EMEA (Agencia Europea del Medicamento). Los datos específicos obtenidos se detallan en la Tabla II.

\section{Análisis microbiológico.}

Se realizaron ensayos microbiológicos para asegurar que la suspensión celular obtenida estaba libre de patógenos microbianos. Para ello se realizaron tinciones de Gram y cultivo durante al menos 72 horas en medio agarchocolate que permite el crecimiento de multitud de cepas bacterianas.

No se obtuvo crecimiento de colonias en ningún caso, y las tinciones de Gram fueron siempre negativas en todas las muestras analizadas $(\mathrm{n}=24)$.

\section{Análisis de eficacia (ensayos de potencia)}

Para demostrar la funcionalidad de las células aisladas se realizaron diversos ensayos de potencia como: siembra de células FVE en matrigel (ensayo de angiogénesis) o inhibición de la proliferación de PBMCs -células mononucleares de sangre periférica-(ensayo de inmunomodulación).

Los ensayos de cultivo en matrigel mostraron que las células eran capaces de asociarse y formar estructuras complejas en matrigel, en muchos casos con marcado positivo para el marcador CD31 (células endoteliales) (Fig. 5).

La incubación de células FVE en presencia de PBMCs demostró la capacidad inmunomoduladora de estas células mediante la inhibición de la proliferación de linfocitos previamente activados con fitohemaglutinina.

Las células FVE en cultivo también demostraron capacidad de diferenciación hacia distintos linajes celulares mesodérmicos mediante estimulación con diferentes medios inductivos (diferenciación adipogénica, condrogénica y osteogénica).

\section{Discusión}

El análisis de los resultados obtenidos indica que el dispositivo GID SVF-1 y el método descrito permiten un aislamiento rápido (aproximadamente en 1 hora) y eficiente (en torno a 600.000 células nucleadas por gramo de tejido adiposo procesado) de células de la FEV a partir de lipoaspirados humanos.

Este dispositivo cerrado, que puede utilizarse en el quirófano durante un mismo procedimiento quirúrgico para procesar tejido adiposo humano, mantiene un am- 
biente estéril durante todo el proceso, como así lo demuestran los ensayos microbiológicos realizados (ausencia de colonias) y los bajos niveles de endotoxinas obtenidos.

En cuanto al rendimiento celular está en el mismo rango, o es incluso superior, a otras tecnologías disponibles de forma comercial $(15,16)$. Una de las grandes ventajas que ofrece este dispositivo es el que permite procesar volúmenes grandes de tejido adiposo (hasta $350 \mathrm{cc}$ de tejido adiposo en cada dispositivo, y hasta 4 dispositivos a la vez, un total de $1400 \mathrm{ml}$ ) para el aislamiento celular.

Todos los análisis de seguridad realizados al efecto indican que la tecnología es segura, con niveles de endotoxinas muy bajos y ausencia total de contaminación en la población celular (FVE) aislada.

Los ensayos de potencia realizados (inmunomodulación y angiogénesis) con la población celular obtenida utilizando el dispositivo GID SVF-1, indican que estas células son funcionales y podrían desempeñar funciones relacionadas con el control de la respuesta inmune y la formación de nuevas redes vasculares, como también han demostrado otros autores $(6,9)$.

\section{Conclusiones}

La técnica y el dispositivo GID SVF-1 utilizados permiten aislar de forma sencilla, rápida y eficaz células de la fracción estromal vascular a partir de lipoaspirados humanos. Estas células pueden emplearse con distintos fines terapéuticos, partiendo de tejido adiposo humano y dentro de un mismo procedimiento quirúrgico, con seguridad.

\section{Agradecimientos}

Nos gustaría agradecer al personal del laboratorio de la clínica USP Palmaplanas, en especial a las Drs. Alcoceba y Ghio, su inestimable ayuda en el procesamiento de muestras para análisis bioquímico y microbiológico.

\section{Dirección del autor}

Dr. Severiano Dos-Anjos

Stem Center SL

Clínica Palmaplanas

Camí dels Reis 308

07010 Palma de Mallorca, España

e-mail: severiano.dosanjos@stem-center.com

\section{Bibliografía}

1. Pretheeban, $\mathbf{T}$., et al.: Role of stem/progenitor cells in reparative disorders. Fibrogenesis Tissue Repair. 2012; 5 (1): $20-32$.
2. Gimble, J.M., A.J. Katz, and B.A. Bunnell.: Adiposederived stem cells for regenerative medicine. Circ. Res. 2007; 100 (9): 1249-1260.

3. Yang, X.F., et al.: High efficient isolation and systematic identification of human adipose-derived mesenchymal stem cells. J. Biomed. Sci. 2011; 18: 59-67.

4. Zuk, P.A., et al.: Multilineage cells from human adipose tissue: implications for cell-based therapies. Tissue Eng, 2001.7 (2): 211-228.

5. Rodriguez, J.P., et al.: Autologous stromal vascular fraction therapy for rheumatoid arthritis: rationale and clinical safety. Int. Arch. Med. 2012; 5: 5-14.

6. Koh, Y.J., et al.: Stromal vascular fraction from adipose tissue forms profound vascular network through the dynamic reassembly of blood endothelial cells. Arterioscler. Thromb. Vasc. Biol. 2011; 31(5): 1141-1150.

7. Astori, G., et al.: "In vitro" and multicolor phenotypic characterization of cell subpopulations identified in fresh human adipose tissue stromal vascular fraction and in the derived mesenchymal stem cells. J. Transl. Med. 2007; 5: 55-65.

8. Bunnell, B.A., et al.: Differentiation of adipose stem cells. Methods Mol. Biol. 2008: 456: 155-171.

9. Kachgal, S. and Putnam, AJ.: Mesenchymal stem cells from adipose and bone marrow promote angiogenesis via distinct cytokine and protease expression mechanisms. Angiogenesis. 2011; 14(1): 47-59.

10. Puissant, B., et al.: Immunomodulatory effect of human adipose tissue-derived adult stem cells: comparison with bone marrow mesenchymal stem cells. Br. J. Haematol. 2005; 129(1): 118-129.

11. Gonzalez-Rey, E., et al.: Human adult stem cells derived from adipose tissue protect against experimental colitis and sepsis. Gut. 2009; 58 (7): 929-939.

12. Salgado, A.J., et al.: Adipose tissue derived stem cells secretome: soluble factors and their roles in regenerative medicine. Curr. Stem Cell. Res. Ther. 2010; 5 (2): 103110 .

13. Casteilla, L., et al.: Adipose-derived stromal cells: Their identity and uses in clinical trials, an update. World J. Stem Cells. 2011; 3(4): 25-33.

14. Tholpady, S.S., et al.: Adipose tissue: stem cells and beyond. Clin Plast Surg. 2006; 33 (1): 55-62.

15. Guven, S., et al.: Validation of an automated procedure to isolate human adipose tissue-derived cells by using the Sepax(R) technology. Tissue Eng Part C Methods. 2012; 18 (8): 575-582.

16. Lin, K., et al.: Characterization of adipose tissue-derived cells isolated with the Celution system. Cytotherapy. 2008; 10 (4): 417-426.

17. Benito Ruiz, J.: Injertos de tejido adiposo: variables que influyen en la viabilidad del adipocito y de las células madre mesenquimales. Cir. plást. iberolatinoam.,2011, 37 (4): 311-318.

18. Almeida, K. A. et al.: Fracción vascular estromal de tejido adiposo: cómo obtener células madre y su rendimiento de acuerdo a la topografía de las áreas donantes: estudio preliminar. Cir. plást. iberolatinoam., 2008, 34 (1): 71-77. 